\title{
Commentary: A lesson from a zebra
}

Nels D. Carroll, MD, and Dawn S. Hui, MD

\footnotetext{
From the Department of Cardiothoracic Surgery, University of Texas Health Science Center at San Antonio, San Antonio, Tex.

Disclosures: Authors have nothing to disclose with regard to commercial support.

Received for publication May 3, 2019; accepted for publication May 3, 2019; available ahead of print June 27, 2019.

Address for reprints: Dawn S. Hui, MD, 7703 Floyd Curl Dr, Suite 211L, San Antonio, TX 78229 (E-mail: huid@ uthscsa.edu)

J Thorac Cardiovasc Surg 2020;159:e165-6

0022-5223/\$36.00

Copyright (C 2019 by The American Association for Thoracic Surgery

https://doi.org/10.1016/j.jtcvs.2019.05.005
}

In this edition of the Journal, Koyama and colleagues ${ }^{1}$ present a timely description of a rare entity. Calcified amorphous tumor is a seldom seen intracardiac process for which surgical resection is recommended. Koyama and colleagues ${ }^{1}$ were presented with an elderly patient with symptomatic aortic stenosis, for whom they appropriately considered transcatheter aortic valve replacement (TAVR). Careful review of preoperative imaging, however, revealed an encapsulated mass between the left coronary and noncoronary cusps. This finding prompted a change to open surgical excision.

The gelatinous contents of this tumor would likely have been expelled from the calcified housing on transcatheter valve deployment. Fortunately, this potential embolic risk was averted. In the era before TAVR, such a finding might have represented little more than a curiosity to the cardiac surgeon. This case, however, illustrates quite succinctly the importance of involvement in preoperative planning and careful assessment of imaging in contemporary practice.

Data continue to emerge to support the implementation of TAVR in younger and healthier patients. The recent updates from the PARTNER 3 (PARTNER 3 Trial The Safety and Effectiveness of the SAPIEN 3 Transcatheter Heart Valve in Low Risk Patients With Aortic Stenosis [P3]) and Evolut (Evolut Surgical Replacement and Transcatheter Aortic Valve Implantation in Low-Risk Patients) clinical trials only serve to bolster our confidence regarding the safety of deployment of TAVR in low-risk patients. ${ }^{2,3}$ The evolution of this technology represents an exciting frontier, but with change comes uncertainty. What are the implications?

The heart team approach adopted by many centers, which advocates for multidisciplinary planning, was built around the concept of treating very sick patients with a new technology. ${ }^{4}$ Although it continues to evolve, TAVR is no longer a new technology. As TAVR is applied to a larger number of patients, many with far fewer comorbidities, the value of the disease.

\section{References} e161-3.

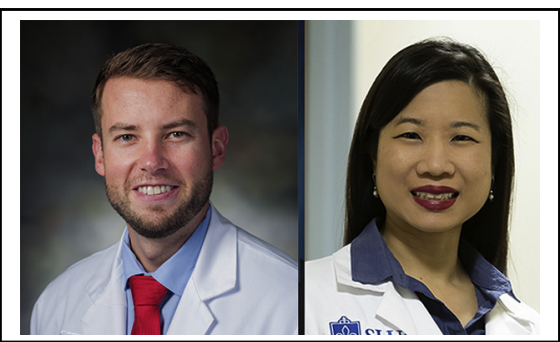

Nels D. Carroll, MD, and Dawn S. Hui, MD

Central Message

A case report of a rare entity highlights the need for cardiothoracic surgeons to remain engaged and involved in the era of transcatheter valve therapies.

See Article page e161.

heart team and the roles therein will inevitably come under question. Does an experienced interventional cardiologist, who has previously collaborated with a surgical team on many TAVR cases for patients at high and intermediate risk, still need to consult his or her surgical colleagues to plan for TAVR valve deployment in a low-risk patient?

The answer is most certainly yes. Surgical expertise and wisdom in patient selection, as demonstrated here, are critical to the safe treatment of aortic valve disease. This conclusion, however, will not be apparent to all. More than ever, the experience and wisdom of the surgeon must extend beyond the operating room. It is imperative that we continue to demonstrate value in this arena, that we avoid the allure of passive participation.

Koyama and colleagues ${ }^{1}$ are to be commended both for their excellent management of this patient and for contributing their experience with this uncommon tumor. Although they report on an isolated case, the implications reach beyond it and prompt reflection. Just as the surgeon leaders who pioneered TAVR remain at the forefront of transcatheter technology investigations and refining the concept of the heart team, ${ }^{2,3,5}$ so should practicing surgeons remain engaged in the evolving care of patients with valvular

1. Koyama Y, Tsujimoto S, Yamamoto M. Calcified amorphous tumor in the aortic valve identified by computed tomography. J Thorac Cardiovasc Surg. 2020;159: 
2. Mack MJ, Leon MB, Thourani VH, Makkar R, Kodali SK, Russo M, et al; PARTNER 3 Investigators. Transcatheter aortic-valve replacement with a balloonexpandable valve in low-risk patients. N Engl J Med. 2019;380:1695-705.

3. Popma JJ, Deeb GM, Yakubov SJ, Mumtaz M, Gada H, O'Hair D, et al; Evolut Low Risk Trial Investigators. Transcatheter aortic-valve replacement with a self-expanding valve in low-risk patients. N Engl J Med. 2019;380:1706-15.
4. Sintek M, Zajarias A. Patient evaluation and selection for transcatheter aortic valve replacement: the heart team approach. Prog Cardiovasc Dis. 2014;56: 572-82.

5. Coylewright M, Mack MJ, Holmes DR Jr, O'Gara PT. A call for an evidence-based approach to the heart team for patients with severe aortic stenosis. J Am Coll Cardiol. 2015;65:1472-80. 